\title{
Suscetibilidade às inundações do Complexo Industrial Portuário de Suape - PE
}

Susceptibility to mass movements and floods of the Port Industrial Complex of Suape - PE.

Silva ${ }^{1}$, J. C.; Silva ${ }^{1}$ I. A. S.; Silva² H. P. B.;

jeissy_geo@hotmail.com

\begin{abstract}
Resumo
Para a construção e desenvolvimento do Complexo de Suape - CIPS foi necessária uma grande mudança na configuração da sua paisagem, pois necessitou de uma grande infraestrutura, intensificando o fluxo migratório e consequentemente a necessidade de uma grande demanda de serviços para atender não só sua construção, mas também a população que iria trabalhar nela. Localizada em uma área que já sofre pressão antrópica desde o período colonial, as pressões decorrentes das atividades antropogênicas foram se intensificando com o desenvolvimento do complexo, que compreende planícies de origem fluvial e fluviomarinha, áreas naturalmente alagáveis que foram ocupadas e edificadas para atender as atividades industriais e portuárias. Para realização da presente pesquisa foi utilizado o sistema de informação geográfica - SIG dos municípios do Cabo de Santo Agostinho e Ipojuca, disponibilizado pelo Serviço Geológico do Brasil - CPRM na escala de 1:25.000.

Verificou-se que a retirada da vegetação nativa, as edificações, a agropecuária, as atividades relacionadas ao Porto-Indústria e as características ambientais de Suape, favoreceram a ocorrência de inundações, prejudicando as próprias atividades ali exercidas e que são extremamente importantes para a economia de Pernambuco e principalmente as vidas envolvidas e dependentes dessa dinâmica.
\end{abstract}

Palavras-chave: Suscetibilidade. Suape. Inundações.

\begin{abstract}
For the construction and development of the Suape Complex - CIPS has required a major change in the configuration of its landscape, it required a great infrastructure, intensifying the migratory flow and hence the need for a high demand for services to meet not only its construction, but also the people who would work on it. Located in an area already suffering anthropic pressure from the colonial period, the pressures resulting from anthropogenic activities have been intensified with the development of complex, comprising plains river and fluvial-marine origin, naturally flooded areas that were occupied and built to meet the activities industrial and port. To carry out this research we used the geographic information system - GIS municipalities of Cabo de Santo Agostinho and Ipojuca, provided by the Geological Survey of Brazil - CPRM on the scale of 1: 25,000. It was found that the removal of native vegetation, buildings, agriculture, activities related to the port-industry and environmental characteristics of Suape, favored the occurrence of floods, damaging their own there exercised activities, which are extremely important to the economy Pernambuco and especially the lives involved and dependent on this dynamic.
\end{abstract}

Keywords: Susceptibility. Suape. Flooding.

\section{INTRODUÇÃO}

As intervenções antropogênicas, principalmente as relacionadas às áreas urbanas, cada vez mais crescentes podem impactar o meio ambiente de diferentes formas. Como nem todas as áreas favorecem a construção das cidades, as que tornam a urbanização possível sofrem com as pressões que envolvem a ocupação. Em cidades de países em desenvolvimento e subdesenvolvidos (principalmente) os impactos dos processos que ali ocorrem são ainda mais danosos, pois contam com o despreparo da população frente ao problema, e dos órgãos governamentais no que concerne o nível tecnológico e ações de mitigação. 
Os recursos hídricos são um dos principais alvos das intervenções humanas, pois é um bem essencial à vida e a qualquer atividade socioeconômica, por isso desde a Antiguidade sua importância era reconhecida e sua adjacência povoada, semelhantemente à atualidade. Para Sergipe (2009 apud GUERRA et al., 2011 pág. 75), as intervenções nos recursos hídricos foram definidas como " toda e qualquer atividade, obra ou empreendimento que altere as condições de escoamento das águas, criando obstáculos, produzindo modificações ou perturbando o fluxo dessas águas". Entre os principais tipos de intervenções, inclui-se: canalização, obras de drenagem urbana, saneamento, retificação, povoamento etc.

\begin{abstract}
Os impactos causados pela urbanização em um ambiente natural podem ser constatados a partir da análise do ciclo hidrológico. Qualquer meio natural tem sua forma determinada principalmente pela ação das águas entre outros condicionantes físicos. As águas pluviais são dissipadas através da evapotranspiração, infiltração e escoamento superficial. Com o crescimento dos centros urbanos, todos estes processos são reduzidos drasticamente, o que faz aumentar o escoamento, encurtando o seu tempo de concentração, causando graves reflexos nos cursos de drenagem natural, provocando erosão, assoreamento e enchentes. As enchentes aumentam sua frequência e intensidade devido à ocupação do solo com superfícies impermeáveis e construções inadequadas como pontes e aterros. (BARBOSA, 2006, pág. 31)
\end{abstract}

A exposição aos riscos sejam eles operantes no meio físico ou social, torna vulnerável parte da população. O conceito de vulnerabilidade ambiental adotado por Tagliani (2003 apud Oliveira 2011, p. 45) significa a maior ou menor susceptibilidade de um ambiente a um impacto potencial provocado por um uso antrópico qualquer. Para Alcântara et al. (2013 p.560) "para cada arranjo espacial de uso e ocupação de uma determinada área há certo grau de vulnerabilidade ambiental associado, cabendo ao pesquisador identificar o conjunto específico de problemas ambientais".

Diferentes autores apresentam diferentes conceitos sobre a vulnerabilidade, contudo, segundo a Embrapa (2010 pg. 11), comumente os estudos apontam alguns pontos em comum, como: "exposição de um sistema à perturbações, sensibilidade do meio e capacidade adaptativa, sendo necessário o pronto esclarecimento desses conceitos em análises de vulnerabilidade.” Este mesmo autor considera a vulnerabilidade, como a susceptibilidade de um sistema à degradação ambiental.

O Complexo Industrial Portuário de Suape - CIPS trouxe grande dinamicidade à microrregião em que está inserido, graças aos investimentos relacionados principalmente a refinaria, estaleiro, siderurgia e turismo. Essa dinamicidade leva a uma mudança na configuração da sua paisagem, causando impactos no meio ambiente e aumentando a necessidade de ofertas de serviços, como emprego, habitação, transportes, saúde entre outros. 
O CIPS é uma área que concentra grandes investimentos em vários setores da economia, o desenvolvimento das suas potencialidades exige mais mão de obra, o que ocasionará uma intensificação no fluxo migratório, esse aumento no contingente populacional necessitará de mais ofertas de serviços básicos. Sua construção e as diversas atividades diretamente relacionadas ao complexo causam pressões no sistema ambiental que associado as características do meio físico biótico, favorecem a ocorrência de processos como deslizamentos e inundações.

. Como nem todas as áreas favorecem a construção das cidades, as que tornam a urbanização possível sofrem com as pressões que envolvem a ocupação. Em cidades de países em desenvolvimento e subdesenvolvidos (principalmente) os impactos dos processos que ali ocorrem são ainda mais danosos, pois contam com o despreparo da população frente ao problema, e dos órgãos governamentais no que concerne o nível tecnológico e ações de mitigação.

\section{METODOLOGIA}

2.1 Localização e Caracterização da Área de Estudo

Localiza-se entre os municípios de Ipojuca e Cabo de Santo Agostinho, como pode ser observado na figura 1 , distante $40 \mathrm{~km}$ da capital pernambucana, situado no litoral Sul entre a foz dos rios Massangana e Ipojuca, sendo cortado ainda pelo rio Tatuoca. Sua latitude e longitude são respectivamente $08^{\circ} 24^{\prime} \mathrm{S}$ e $34^{\circ} 57^{\prime} \mathrm{W}$. O acesso se dá pelos meios rodoviários, através da $\mathrm{BR}-101$ e PE-28 e PE-060, ferroviários, através da EF-101, estações do Cabo e Ponte dos Carvalhos, dutoviários, para transportes de cargas em casos específicos e marítimos, através do Porto Interno e Porto Externo. A área de estudo é formada basicamente pela Bacia Pernambuco, porém outras unidades são encontradas, sendo identificadas como as formações: Cabo, Ipojuca e Estivas, porém Lima Filho et al. (apud CPRM, 2001 pg. 33) identificaram outra unidade que posteriormente foi denominada de Formação Algodoais. O Compartimento Geomorfológico do Complexo de Suape é constituído por duas grandes unidades: Planície Costeira e pelo Domínio de Patamares. Sobre os solos, o Complexo Industrial Portuário de Suape predomina nove tipos de classes de solos (algumas com mais de uma subdivisão), são eles: Areia Quartzosa; Areias Quartzosas Marinhas + Podzol Hidromórfico; Gleissolos; Podzólico Hidromórfico; Latossolo Amarelo; Podzólico Amarelo; Podzólico Vermelho - Amarelo; Solo de Mangue; Terra Roxa Estruturada. A vegetação da área de estudo é caracterizada pela CPRM (2013) pelo bioma da Floresta Tropical Atlântica e pela vegetação de mangue. 

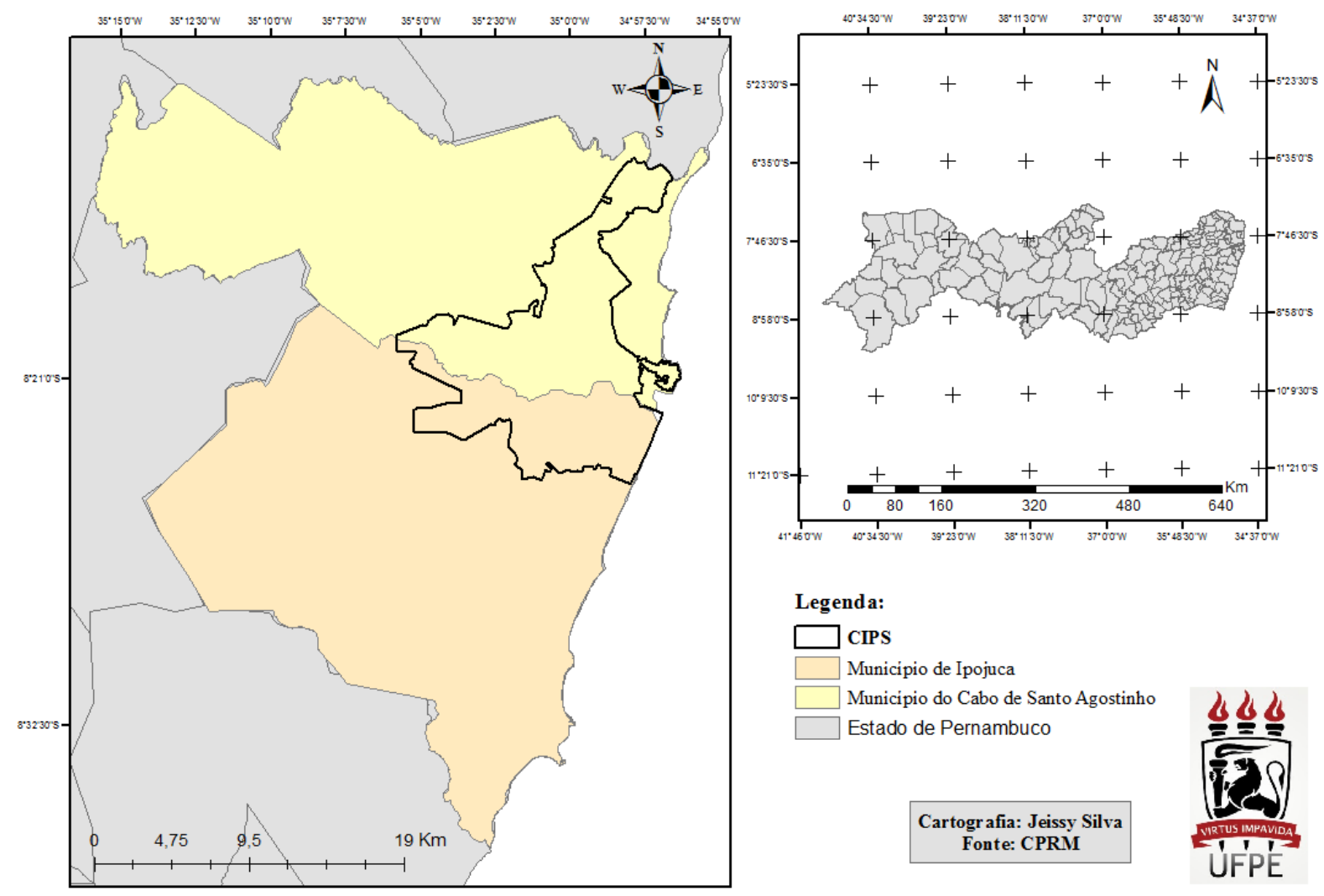

Figura 1: Localização da área de estudo. Fonte: CPRM (2013). Organizado pela autora.

De acordo com o estudo da CPRM (2013 pg. 651) o clima da microrregião de Suape segundo a classificação de Köppen é As', assim como quase toda a parte sul da região metropolitana do Recife. O clima As' é caracterizado como sendo quente e úmido com chuvas antecipadas no outono, a precipitação média é de $1800 \mathrm{~mm}$ aproximadamente, sua temperatura média é de $26^{\circ} \mathrm{C}$, podendo ter a variação de $4^{\circ} \mathrm{C}$, decorrente da amplitude térmica anual. A microrregião de Suape é composta por 4 bacias hidrográficas, contudo, apenas duas estão inseridas no CIPS, a GL - 2 (grupo de rios litorâneos) e a bacia do rio Ipojuca.

\subsection{Metodologia Adotada}

Para a produção das cartas de suscetibilidade às inundações e aos movimentos de massa foi utilizado o SIG dos municípios de Ipojuca e Cabo de Santo Agostinho disponibilizado pelo Serviço Geológico do Brasil - CPRM, que utiliza a escala 1:25.000. O SIG seguiu diretrizes da Política Nacional de Proteção e Defesa Civil (PNPDEC), estabelecida pela Lei Federal 12.608/2012 (CPRM, 2013 pg. 1), a proposta desse mapeamento é identificar e avaliar as áreas suscetíveis a processos como deslizamentos, corridas de massa, inundações e enxurradas, pois entende-se que o conhecimento sobre a vulnerabilidade ambiental associada ao crescimento urbano e aos impactos 
gerados por ele, é decisivo ao planejamento e as tomadas de decisões e portanto diminuindo a probabilidade de desastres. Para identificação e determinação deste tipo de suscetibilidade foram utilizadas duas abordagens, a primeira seguiu os critérios da engenharia, como os conceitos de hidráulica e da hidrologia, baseando-se em modelagens da chuva- vazão em relação ao canal ou a planície de inundação, a segunda é baseada na perspectiva mais geográfica, analisando de forma descritiva - qualitativa.

\begin{abstract}
A abordagem adotada para o mapeamento de áreas suscetíveis a inundações apoia-se nos fatores permanentes, ou seja, nas condições predisponentes dos terrenos, principalmente nas características geológicas, topográficas e morfológicas das bacias que tendem a favorecer o transbordamento do nível d'água, por ocasião de chuvas intensas. A rigor, a consideração dos períodos de retorno das chuvas, associados aos graus de alta, média e baixa ocorrência, seria compatível com a elaboração de mapas de perigo e não de suscetibilidade e, desse modo, não são tratados no presente mapeamento. Busca-se possibilitar a compreensão da dinâmica hidrológico-geomorfológica de forma padronizada e prática, classificando a suscetibilidade a inundações em bacias de drenagem que podem abranger vários municípios. (CPRM, 2013 pg. 18).
\end{abstract}

Após a obtenção dos dados, suas informações foram organizadas e editadas no software Arcgis 10.2.2, onde foi possível visualizar os atributos selecionados e destacá-los na área de estudo. Foram analisados também os dados referentes à precipitação disponibilizados pelo Instituto Nacional de Meteorologia - INMET, para os anos de 1985 a 2015.

\title{
3. RESULTADOS E DISCUSSÃO
}

As inundações são conceituadas por Ramos (2011 pág.11) como, fenômenos hidrológicos extremos e que podem ter causas naturais ou antrópicas, caracterizados pela imersão de uma área que antes era emersa. Ressalta-se que muitas vezes o conceito de inundações é confundido com o de cheia, caracterizada por ter um padrão predominantemente temporário, e as inundações, mesmo que na maioria das ocorrências, possua caráter temporário, pode vir a ser permanente. A referida autora classifica os principais tipos e fatores que causam as inundações são eles:

- Cheia (inundação fluvial)

Chuvas abundantes e/ou intensas; fusão da neve ou do gelo; efeito combinado chuva somados ao efeito das marés e/ou storm surge; obstáculos ao escoamento fluvial ou demolição dos obstáculos

- Inundação de depressões topográficas

Subida do lençol freático (natural ou artificial*); retenção da água da precipitação por um solo ou substrato geológico de permeabilidade muito reduzida; cheias.

- Inundação costeira 
Storm surge; tsunamis ou maremoto; subida eustática do nível do mar; sismos com fenômenos de subsidência tectônica.

- Inundação urbana

Chuva intensa; sobrecarga dos sistemas de drenagem artificiais; subida do lençol freático (natural ou artificial*); cheias.

$\mathrm{Na}$ área de estudo predomina os tipos de inundações urbana e fluvial, pois sofre influência das atividades relacionadas ao porto-indústria, bem como de toda infraestrutura necessária para a seu funcionamento, e recebe a vazão dos rios. As inundações são comuns em áreas de baixa declividade, como planícies e terraços fluviais, tendo como principal condicionante o volume de distribuição da precipitação; tipo e densidade da cobertura vegetal; substrato geológico; geometria do canal fluvial; cobertura pedológica (GUERRA, 2011).

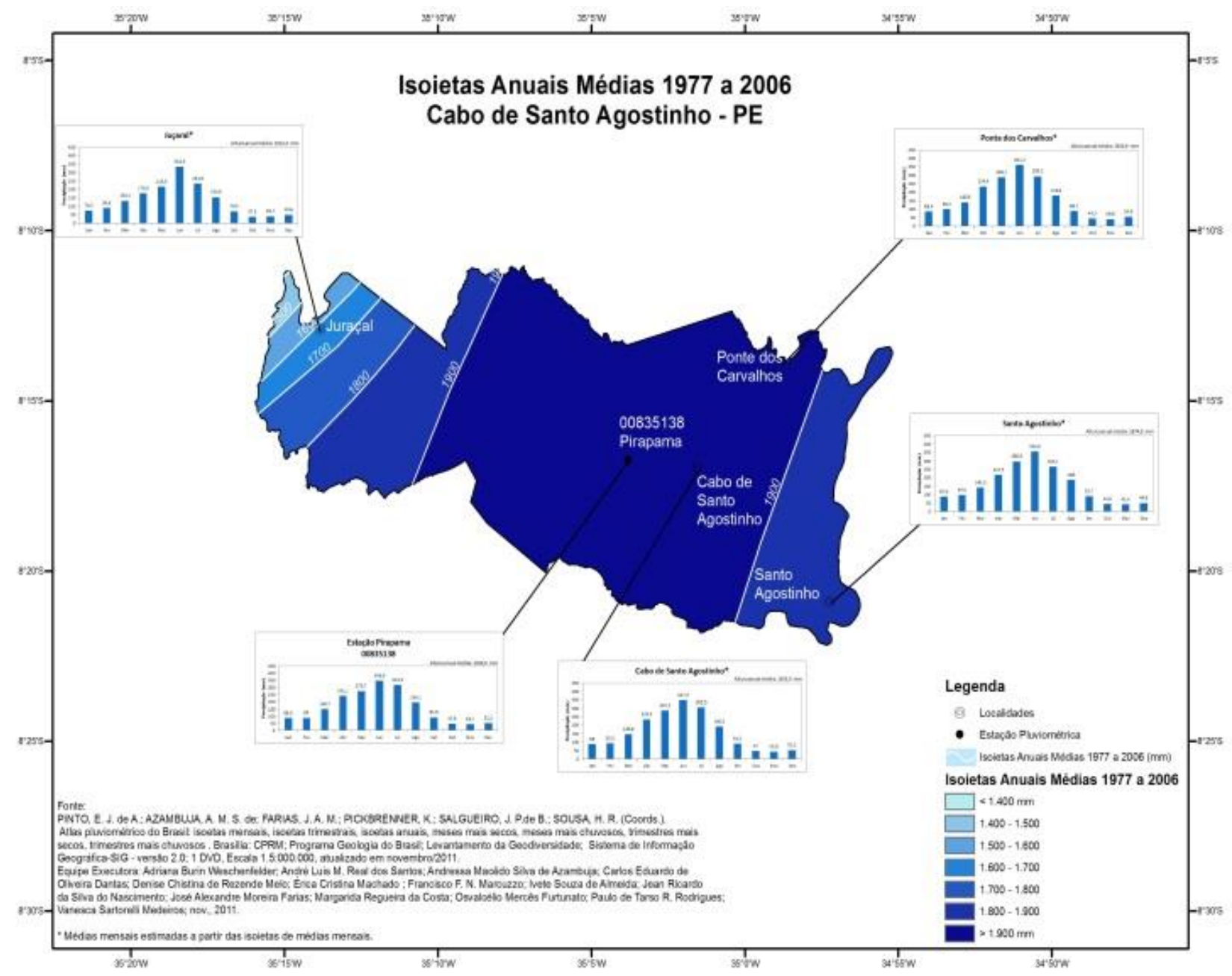

Figura 2: Isoieta do município de Cabo de Santo Agostinho. Fonte: CPRM (2013). 


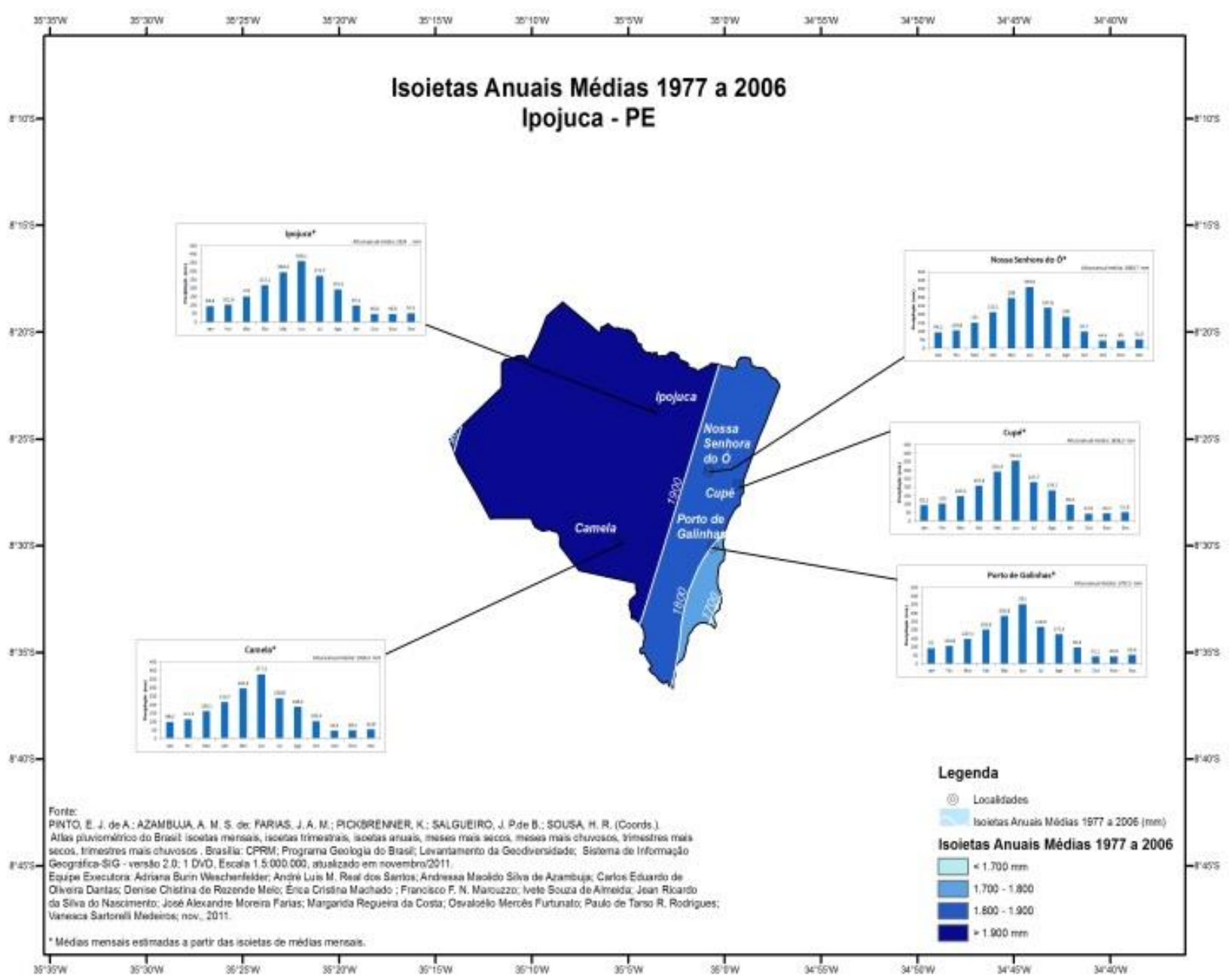

Figura 3: Isoieta do município de Ipojuca. Fonte: CPRM (2013).

Conforme observado nas isoietas para os municípios do Cabo de Santo Agostinho e Ipojuca, detalhado nas figuras 2 e 3, a área de estudo concentrou uma média de volume da precipitação entre 1.800 a $1.900 \mathrm{~mm}$, no período de 1977 a 2006. Analisando os dados pluviométricos disponibilizados pelo INMET (acesso em 02/05/2016) entre os anos de 1985 e 2015, constatou-se que totalizaram-se 11.295 dias, dentre os quais 6.807 dias corresponderam aos chuvosos $(60,27 \%)$.

A mediana dos dias de chuva resultou em 4mm, o que significa que $50 \%$ dos anos estão abaixo de $4 \mathrm{~mm}$, já o $3^{\circ}$ quartil resultou em $11,6 \mathrm{~mm}$, o que significa que $75 \%$ dos dias de chuva registrados na estação do Recife (Curado) apresentaram valores abaixo de 11,6mm o maior evento registrado foi 235mm (em 24/051986). Apenas 273 dias apresentaram precipitação igual ou maior que $50 \mathrm{~mm}(2,42 \%$ do intervalo de tempo), ou seja essa é a probabilidade de ocorrerem eventos acima de 50mm considerando os dados dos últimos 30 anos. Apenas 0,4\% (45) dos eventos foram iguais ou superiores a 100mm, ressalta-se que 3 dias de saturação de $100 \mathrm{~mm}$ já pode desencadear um deslizamento, já os escorregamentos em geral precisam de saturação do solo ao longo de alguns dias ou um evento muito extremos em um único dia, enquanto as inundações podem ocorrer com 
uma precipitação intensa de 20min a depender da vasão e da taxa de impermeabilização. A figura 4 apresenta a identificação das áreas de suscetibilidade à inundação da área de estudo.
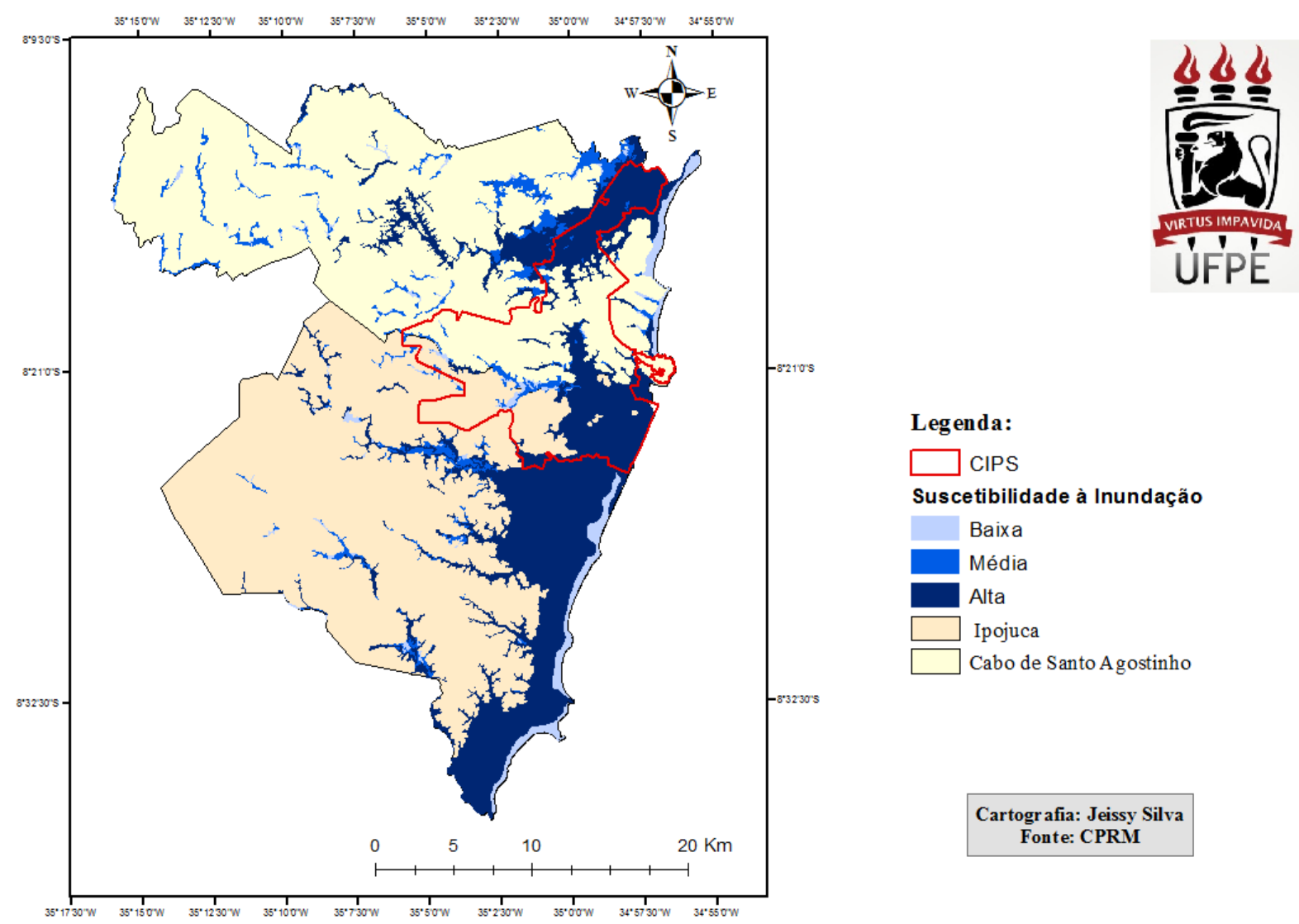

Figura 4. Mapa de Suscetibilidade à inundação do Complexo Industrial Portuário de Suape. Fonte: CPRM (2013).

Organizado pela autora.

O mapa de suscetibilidade à inundação da área de estudo apresenta três classes, são elas: Baixa, Média e Alta. Constatou-se as áreas de Média e Alta suscetibilidade estão associadas predominantemente às planícies de origem fluvial e fluviomarinha, e às áreas urbanas edificadas que correspondem a infraestrutura do Complexo. Sendo assim conclui-se que as intervenções antropogênicas realizadas na área de estudo intensificou a suscetibilidade à inundação, potencializando a predisposição natural.

Botelho (2004 apud GUERRA, 2011, pág. 86) aponta que os principais fatores agravantes da inundação urbana são: Dimensionamento inadequado de projeto; Obstrução de bueiros; Obras inadequadas; Adensamento populacional; Interferência física (principalmente alteração da drenagem e assoreamento); Lençol freático alto e Impermeabilização do solo. 
Vale ressaltar que as fortes chuvas podem ocasionar a erosão dos solos, principalmente em áreas de clima tropical, principalmente quando concentra seu período chuvoso em determinada estação do ano, o que potencializa sua ação (GUERRA, 2011). A erosão está mais relacionada às áreas de colinas, pois a declividade é fator bastante relevante. $\mathrm{Na}$ área de estudo, foram identificadas a forma erosiva do tipo ravina, que correspondem a sulcos que se originam em solos com manejo inadequado e por isso sofreram processo de erosão decorrente do escoamento da água.

\section{CONSIDERAÇÕES FINAIS}

A presente pesquisa trouxe a discussão os problemas decorrentes da dinâmica espacial no entorno do Complexo de Suape que potencializam a ação das chuvas, ocasionando assim eventos de inundações. Uma construção dessa magnitude trouxe além das vantagens econômicas, impactos para a região em que foi construída, como desmatamento, realocações e interferência no tráfego de moradores e pessoas, mudanças nas fontes de rendas dos moradores, mudanças do ecossistema marinho, impactos no uso do solo e etc. Ao analisar a predisposição natural, como pluviosidade, tipos de solo e terreno, por exemplo, e associando a configuração espacial, ficou constatado que a área de estudo apresenta três níveis de suscetibilidade aos eventos mencionados acima, classificados em: Baixo, Médio e Alto.

Ressalta-se que empresa Suape, responsável pela administração do complexo realizou todos os estudos exigidos pela legislação ambiental brasileira, estudo esses que são contínuos e são associados às ações mitigadoras e minimizadoras dos impactos, como trabalhos de Educação Ambiental, área de vegetação preservada, construção de habitacionais para acomodação dos moradores indenizados entre outras. Contudo tais ações não se mostram satisfatórias perante os impactos e riscos que expõe essa região. Portanto, necessita-se evidentemente e urgentemente de mais estudos, discussões e exposição dessa problemática, associados a ações que de fato tragam mudanças.

\section{REFERÊNCIAS}

GUERRA, Antônio José Teixeira. Geomorfologia Urbana/ Antônio José TeixeiraGuerra (org). Rio de Janeiro: Bertrand Brasil, 2011.

GUERRA, Antônio José Teixeira. Encostas Urbanas. In: Geomorfologia Urbana/ Antônio José Teixeira Guerra (org). - Rio de Janeiro: Bertrand Brasil, 2011.

ALCÂNTARA, Romilson dos Santos. Vulnerabilidade Socioambiental do Bairro do Paracuri, Icoaraci-Pa. Anais do VII Congresso Brasileiro de Geógrafos. 2014. 
de São Paulo ; Brasília, DF : CPRM - Serviço Geológico do Brasil, 2014. - (Publicação IPT ; 3016).

CONDEPE/FIDEM. Perspectivas de desenvolvimento e crescimento do Complexo Industrial Portuário de Suape. 2008

EMBRAPA. Análise da Vulnerabilidade Ambiental. Fortaleza - CE. 2010.

RAMOS. Catarina. Perigos Naturais Devido a Causas Meteorológicas: O Caso das Cheias e Inundações. Centro de Estudos Geográficos, Instituto de Geografia e Ordenamento do Território, Universidade de Lisboa.

CPTEC - INPE - Centro de Previsão do Tempo e Estudos Climáticos do Instituto Nacional de Pesquisas Espaciais http://www.inpe.br/ Acesso em 15 de Junho de 2015.

CPRM. http://www.cprm.gov.br/. Cartas de Suscetibilidade a Movimentos Gravitacionais de Massa e Inundações - 1:25.000. SIG. Acesso em 22 de Junho de 2016.

CPRM. www.cprm.gov.br/publique/media/litoralsuldepernambuco.pdf. Acesso em 17de Julho de 2016.

EMBRAPA. Zoneamento Agroecológico do Estado de Pernambuco - ZAPE. Acesso em 22 de Junho de 2016.

INMET. http://www.inmet.gov.br/portal/. BDMEP - Banco de Dados Meteorológicos para Ensino e Pesquisa. Acesso em 5 de Abril de 2016.

BARbOSA, Francisco de Assis dos Reis. Medidas de Proteção e Controle de Inundações Urbanas na Bacia do Rio Mamanguape/PB. Dissertação (Mestrado em Engenharia Urbana). Centro de Tecnologia/Universidade Federal da Paraíba - UFPB.

GOUVEIA, Enildo Luiz. Aspectos Ambientais e Gestão dos Recursos Hídricos no litoral sul da Região Metropolitana do Recife - RMR: O caso da Microrregião de Suape. Dissertação de Mestrado. João Pessoa - PB, 2010.

GUERRA. S. M. S. Cartografia Geológica- Geotécnica de Áreas Costeiras: O exemplo do Complexo de Suape-PE. Tese de Doutorado. Rio Claro, 1998.

OLIVEIRA, Janaina Melo. Ecodinâmica e vulnerabilidade ambiental da zona estuarina do Rio Zumbi, litoral oeste do Ceará. Dissertação de Mestrado. Fortaleza, 2011

Recebido em: 14/08/2016

Aceito para publicação em: 01/10/2016 